\title{
diaphora
}

\section{Sobre o conceito de loucura: das psicoses à experiência social}

\author{
On the concept of madness: from psychoses to social experience
}

\section{Sílvio Camargo}

Resumo: $O$ artigo aborda o conceito de loucura em um diálogo da psicanálise com outros campos do saber, em especial a antipsiquiatria britânica e o pós-estruturalismo de Michel Foucault. A forma de apresentação é o ensaio, na tradição da dialética adorniana. O problema central proposto é a diferenciação subjacente entre as noções de psicose e loucura tomando como referência as obras de Freud e Lacan, em um procedimento de comparação com outros modelos teóricos e epistemológicos. Apresenta-se um privilégio ao conceito de esquizofrenia e sua centralidade em debates sobre psicoses no pensamento contemporâneo. $\mathrm{O}$ estudo é exclusivamente teórico, comparando conceitos e autores e o objetivo é propiciar um olhar crítico, nos moldes da tradição frankfurtiana, quanto à relação entre psicoses e sociedade, sugerindo-se a relevância do conceito de experiência social. Trata-se de um ensaio panorâmico, que pretende contribuir para a compreensão daloucura na sociedadecontemporânea e suas correlatas formas de dominação social.

Palavras chave: Esquizofrenia; Psicanálise; Antipsiquiatria.

\section{Introdução}

Para a tradição psicanalítica, em boa parte dela, 0 antigo conceito de loucura foi subsumido pelo de psicose, embora não possamos dizer se tratar da mesma coisa (Birman, 1989). Quanto às psicoses entendo que há pelo menos duas dimensões distintas sobre o como abordá-las: a clínica, teórica
Abstract: The article addresses the concept of madness in a dialogue between psychoanalysis and other fields of knowledge, in particular British antipsychiatry and Michel Foucault's poststructuralism. The form of presentation is the essay, in the tradition of the adorniana dialectic. The central problem proposed is the underlying differentiation between the notions of psychosis and madness taking as reference the works of Freud and Lacan, in a comparison procedure with other theoretical and epistemological models. A privilege is presented to the concept of schizophrenia and its centrality in debates about psychoses in contemporary thought. The study is exclusively theoretical, comparing concepts and authors and the objective is to provide a critical look, along the lines of the Frankfurt tradition, regarding the relationship between psychoses and society, suggesting the relevance of the concept of social experience. It is a panoramic essay, which aims to contribute to the understanding of madness in contemporary society and its related forms of social domination.

Keywords: Schizophrenia; Psychoanalysis; Antipsychiatry.

e prática, que se debruça em conceituar e compreender a psicose, e a psicossocial, na falta de expressão melhor, que aborda os aspectos institucionais, sociais, políticos e até mesmo ideológicos, sobre o como tais fenômenos subjetivos se processam e são apreendidas pela sociedade. Em muitas análises teóricas as duas dimensões não se separam, caminho que tentarei delinear neste artigo. Trata-se de interpelar o conceito de loucura num diálogo entre

\footnotetext{
1 Bacharel em Filosofia (UFRGS) e Doutor em Sociologia (Unicamp). Email: scccamargo@gmail.com .
} 
psicanálise e teoria social. 0 procedimento metodológico utilizado se refere a uma revisão bibliográfica de natureza crítica estabelecendo comparações entre diferentes autores.

O problema que proponho, enquanto reflexão teórica, éo como podemos enxergar a singularidade e a diferença, na clínica ou fora dela, quando ações ou narrativas de sujeitos não evidenciam, em certos casos, a existência de uma foraclusão que nos permitiria nomear o indivíduo como psicótico. 0 caso emblemático do escritor James Joyce, extensamente tratado por Jacques Lacan (2007), é um ponto de referência para pensarmos sobre aquilo que não se apreende no Simbólico, mas que ao mesmo tempo em seu retorno ao Real não nos possibilita com segurança dizer do indivíduo um psicótico. Pode-se dizer que lidamos com um louco que não é psicótico, neurótico ou perverso, embora possa trazer elementos destes, o que seria, todavia, apreensível por traços que permeiam também o Simbólico e o Imaginário. A pergunta é, assim, o que seria este louco que não se nomeia como psicótico.

0 objetivo do artigo é correlacionar as psicoses, em especial a esquizofrenia, como estrutura clínica, com uma acepção ampliada de laço social, para além das fronteiras da psicanálise, em um diálogo especialmente com a filosofia, a antipsiquiatria e a teoria social, onde seja possível pensarmos, por exemplo, no conceito de experiência social (Camargo, 2019). Embora eu não parta da perspectiva, talvez culturalista, de que a loucura se define como 0 discurso que destoa da norma social, também não nos parece suficiente refletir teoricamente sobre as psicoses exclusivamente como estrutura clínica. Irei privilegiar o conceito de esquizofrenia como expressão clássica da loucura tentando contextualizar sua apreensão pela psicanálise; depois abordar algumas dificuldades quanto ao conceito de loucura adotando como principal referência as contribuições de Jacques Lacan; e por fim, fazer algumas conexões entre teoria psicanalítica das psicoses e teoria social.

\section{Loucura, psicanálise e outros saberes}

Tratar as psicoses como uma questão médica ou de saúde mental é uma abordagem peculiar ao campo da psiquiatria. Neste âmbito, as psicoses são usualmente associadas aos fatores biológicos e neuroquímicos que embasariam sua definição, não obstante certos discursos, mais contemporâneos, de aceitação de características multifatoriais de sua causação, como se tal aceitação representasse um olhar científico mais progressista, em especial quanto à esquizofrenia. Um dos principais procedimentos de autolegitimação da psiquiatria, desde seu surgimento até o presente, éa classificação. A maneira pela qual tal mecanismo é também uma forma de poder já foi apontado por Michel Foucault em diferentes obras (1999; 2014; 2017), e as formas de classificação da psiquiatria se tornaram igualmente distintas daquelas da psicanálise. Cabe perguntamos, por outro lado, como já o fizeram Deleuze e Guattari (2010), em que medida a psicanálise consegue se furtar ao furor positivista e efetivamente falar de psicose como al go que diz respeito ao sujeito e sua singularidade, e não à uma história natural.

A relação da psicanálise com o conceito amplo de loucura não pode ser vista exclusivamente como problema da práxis clínica, mas também como algo da própria ética da psicanálise em sua relação com a Polis. Isto se refere ao fato de que o louco, ou psicótico, possui um sofrimento e existência que está diretamente relacionado com o conjunto das relações familiares, institucionais e históricas em que vive. Se existe uma linguagem da loucura, para parafrasear David Cooper (1978), entende-se, como ele, que esta não se refere tão somente a uma cadeia de significação restrita aos critérios da lógica formal, abstraindo-se das condições materiais e históricas com as quais se relaciona a subjetividade do psicótico.

Associarmos loucura com esquizofrenia é algo que se deve muito mais à história da psiquiatria ao longo do século XX do que a história da psicanálise. Se a psicanálise, especialmente depois de Lacan, passou a enfrentar com maior assiduidade às especificidades do dizer psicótico, mesmo assim não foi a esquizofrenia a estrutura clínica mais frequente a ser pensada pelos psicanalistas. A esquizofrenia sempre foi um desafio para a psicanálise, desde os primeiros escritos de Freud. É curioso que na década de 1950, quando a psiquiatria teve um de seus momentos de mutação com a produção de fármacos para 0 tratamento da esquizofrenia e no Reino Unido a antipsiquiatria esboçava seus primeiros passos (Bosseur, 1976), o ensino de Lacan, que já havia iniciado nos anos 1930 com sua tese de doutorado e o hoje paradigmático caso Aimée, continue a se reportar às psicoses tomando como principais referências os casos de paranoia, com especial atenção para o não menos importante caso Schreber, tema dos seminários de 1955-56 (Lacan, 1988) e do importante ensaio De una cuestión preliminar a todo tratamento posible de las psicoses (Lacan, 2006b) originalmente escrito em 1955.

A psiquiatria contemporânea, por mais avanços que possa ter tido nas últimas décadas, continua a ter como referência de prática científica o seu manual clássico, o DSM, que muito distante se encontra da tradição psicanalítica. Junto a ele, e com as mudanças da contemporaneidade, os chamados transtornos de personalidade, como a bipolaridade e o borderline, eclipsaram em parte a efervescência do conceito de esquizofrenia, que demarcava fortemente o debate sobre loucura entre os anos 1950 e 1970. As chamadas doenças mentais encontraram, por parte da psiquiatria, novas formas de rotulação e nomenclatura, sempre amparadas pela cisão entre 0 normal e o patológico, e pelo poder-saber médico habilitado a emitir cada vez mais rápidos diagnósticos a partir dos sintomas verbalizados pelos indivíduos.

0 advento da psicanálise é concomitante a al guns momentos marcantes na história da psiquiatria moderna, como é 0 caso da criação do conceito de esquizofrenia nos meados do século XX com Bleuler, então associada à noção de demência precoce. Desde o seu "As neuropsicoses de defesa" Freud (1894/1986) se afasta das explicações biologizantes e causais da psiquiatria, sugerindo que as afecções mentais chamadas de psicoses também estão relacionadas a desenvolvimento da libido, muito embora, ao contrário das neuroses, haja nelas uma dificuldade compreensiva quanto à própria possibilidade de desvelamento do inconsciente do psicótico. Isto porque a forma de negação (Verneinug) da psicose se processa de um modo diferente daquele que ocorre com a histeria ou a neurose obsessiva. Há ainda que acrescentarmos que dentre as classificações nosológicas iniciais para as psicoses (esquizofrenia, paranoia e transtorno maníaco-depresivo) a esquizofrenia sempre apareceu, para Freud, muito mais como um contraponto para o objeto da psicanálise, 0 inconsciente, especialmente o do neurótico, do que como uma modalidade de sofrimento psíquico passível de ser desvelado pela teoria e prática psicanalítica. Cabe lembrarmos que o estudo ou caso clínico sobre psicoses que entrou para a história da psicanálise foi sobre um paranoico, Daniel Paul Schreber (Freud, 1911-2006a), cuja loucura foi celebrizada a partir da sua autobiografia, e não através de uma análise empreendida pessoalmente por Freud.

São nos textos da chamada metapsicologia que a questão das psicoses e da esquizofrenia também aparecem, mesmo que timidamente, no pensamento freudiano. Como uma espécie de negativo da própria estruturação do 
inconsciente a psicose se mostra, inicialmente, como uma espécie de limite da psicanálise, limite este que encontrou tentativas de ruptura pelos seguidores de Freud, seja ainda durante sua vida, ou um pouco depois, como são os casos de Jung, Frieda Fromm-Reichmann e Melanie Klein, ou mais tarde, especialmente por Lacan. Mas na letra freudiana alguns detalhes não podem passar despercebidos. Muito diferente da antipsiquiatria dos anos 1950 que buscou desmistificar a loucura como uma "doença", este termo é recorrente no vocabulário freudiano, aliás para se referir não apenas às psicoses, mas também às neuroses e perversões. Mesmo que desmistificando a psicose como algo de origem biológica e natural, ela permanece sendo passível de ser nomeada como uma doença mental. E por estranho que pareça, esta separação entre normal e patológico reapareceu ao longo do tempo mesmo entre parte da literatura psicanalítica.

Ao contrário da psiquiatria de sua época Freud aponta que não apenas as neuroses, mas também as psicoses, são afecções psíquicas que podem ser entendidas a partir de uma teoria da libido. Ao mesmo tempo, o inconsciente, epicentro da psicanálise, só consegue ser acessado e interpretado a partir da análise dos neuróticos, senão, igualmente, pelos sinais que se expressam em sonhos, esquecimentos, chistes e atos falhos, nos tropeços de um modo geral associados ao campo da linguagem. A psicose, por outro lado, diz respeito às possibilidades de um acesso bastante indireto a este inconsciente, como sendo, ao mesmo tempo, expressão de uma impossibilidade de acesso a ele, na medida em os afetos que demarcam experiências traumáticas não encontram uma clara representação quanto ao seu processo de denegação. A libido é investida no próprio eu e não nos objetos, se tratando por isso de doenças que se relacionam ao campo do narcisismo. Colocamo-nos, de qualquer modo, frente a um impasse:

Um motivo premente para nos ocuparmos com a ideia de um narcisismo primário e normal apareceu quando se fez a tentativa de incluir o que sabermos da 'dementia praecox' (Kraepelin) ou esquizofrenia (Bleuler) sob a hipótese da teoria da libido. Esses doentes, que eu sugeri designar como parafrênicos, mostram duas características fundamentais: a megalomania e 0 abandono do interesse pelo mundo externo (pessoas e coisas). Devido a esta última mudança, eles se furtam à influência da psicanálise, não podendo ser curados por nossos esforços (Freud, 1914-2015a, p. 15)

Enquanto que no indivíduo neurótico o recalcamento cria um representante para aquilo que foi recalcado, sendo passivel por isso de transformação através da análise, no caso da psicose, e mais especificamente da esquizofrenia, a rejeição do afeto não encontra uma representação, mas reaparece no próprio eu enquanto separação da realidade, havendo assim, para usarmos uma expressão bastante usual, uma manifestação " a céu aberto" do inconsciente. Desaparece o investimento libidinal nos objetos, e no caso da esquizofrenia as próprias palavras são tomadas como coisas. Na visão de Freud, o esquizofrênico não consegue estabelecer com o analista uma relação de transferência, se constituindo em portador de um sofrimento que manifesta, naquele momento, um limite da própria clínica psicanalítica:
A incapacidade desses pacientes para a transferência - até onde alcança o processo patológico - , a consequente inacessibilidade à terapia, a característica rejeição do mundo externo, 0 surgimento de sinais de um sobre investimento do próprio Eu, 0 desfecho na completa apatia, todos esses traços clínicos parecem condizer perfeitamente com a hipótese de um abandono dos investimentos objetais (Freud, 1915-2015 b, p. 140).

A dificuldade inicial da psicanálise com uma clínica das psicoses não impossibilitou Freud de falar longamente sobre outra doença narcísica, mais tarde retomada por Lacan, que é a paranóia, através do caso clínico exemplar de Schreber, mas com diferentes nuances. Nesse caso, a fixação narcísica dizia respeito não a uma relação entre 0 Eu e realidade objetal, mas entre 0 Eu e 0 outro, considerado como igualmente representante do mundo exterior. Na análise do caso Schreber aparece a afirmação de Freud que virá mais tarde a ser crucial para Lacan, a afirmação de que na paranóia "uma percepção interna é suprimida e, em substituição, seu conteúdo vem à consciência, após sofrer certa deformação, como percepção de fora" (Freud, 1911-2016 a, p. 88), a0 mesmo tempo, Freud inova ao dizer que a formação delirante é um trânsito para o restabelecimento, e não um sintoma da doença. Lembremos que para a psiquiatria de então, e não apenas ela quando se trata de classificar a esquizofrenia, delírios e alucinações se apresentam como a própria manifestação da chamada doença mental.

0 entendimento das psicoses como investimento narcísico de libido, tal como se percebe no caso Schreber, indica ao mesmo tempo que as doenças narcísicas possuem distinções entre si, no caso entre a paranóia e a esquizofrenia, não obstante a dificuldade existente de se estabelecer uma clara distinção entre os conjuntos de sintomas, visto que, conforme o próprio Freud, um indivíduo que tem inicialmente traços paranoicos pode logo em seguida evidenciar um quadro de esquizofrenia e assim por diante (Freud, 19112016a). De qualquer modo, cabe insistir que a nosologia da psicanálise em seus momentos iniciais já expressava uma nítida diferenciação com a psiquiatria.

Tentar desconstruir a ideia de loucura como doença mental está presente na contraposição entre psiquiatria e psicanálise desde o surgimento desta última, muito embora a noção de doença sempre tenha estado presente no vocabulário freudiano. As tentativas de desmistificar a ideia de doença como forma de nomear a loucura foram bem mais visíveis nos chamados movimentos da antipsiquiatria, e no pós-estruturalismo francês, do que na literatura psicanalítica. Poderíamos concordar que parte ou al guns momentos do movimento antipsiquiátrico ressoa certo romantismo, ao situar a loucura em sua relação com a norma social, tornando o problema, no extremo oposto da psiquiatria, em algo de natureza eminentemente social e ideológica, como evidenciam, em muitos momentos, as obras de Thomas Szasz (1978) ou David Cooper (1978).

As dificuldades iniciais de Freud e da psicanálise em lidar com as psicoses, e mais especificamente com a esquizofrenia dizia respeito, como um problema central, em como estabelecer relações de transferência entre paciente psicótico e analista. Dificuldade esta que foi enfrentada pelos discípulos de Freud, más que, conforme entendo, acabou por trazer à tona outro aspecto desta história, o fato de que o analisando psicótico em geral é encontrado e escutado em algum tipo de ambientação que envolve instituições médicas. A maior parte dos relatos que inicialmente apontavam para uma possível clínica das psicoses 
apontam para indivíduos já hospitalizados, ou que passaram por hospitalizações e que, portanto, já teriam passado por algum momento de crise psicótica. Não há como negligenciarmos, nesse sentido, o olhar de Foucault, para quem a loucura em acepção moderna, já transformada em doença, só advém como tal a partir de um saber-poder que se relaciona a algum tipo de instituição disciplinar (Foucault, 2017), como era o caso das instituições hospitalares.

\section{Freud e Lacan}

Oriundo da psiquiatria, o ingresso de Lacan na psicanálise ocorre no âmbito de uma clínica das psicoses, muito embora sua teoria psicanalítica seja em grande medida um diálogo também com a Filosofia. Na biografia de Lacan (Roudinesco, 1994) enxergamos o ano de 1932 como ponto marcante de sua trajetória intelectual, quando ele apresenta uma tese de doutorado "De la psychose paranoïaque dans ses rapports avec la personnalité" que traz 0 caso Aimée, mencionado em grande parte dos comentários sobre o problema das psicoses em Lacan. Aimée era o nome dado por Lacan para Marguerite Anzieu, uma jovem levada a um hospital psiquiátrico de Paris em 1931 após agredir com uma faca a atriz Huguette Dulfos. Transformado em um caso clínico, antes mesmo de Lacan ter se tornado psicanalista, o caso Aimée entrou para a literatura como um caso de paranóia, após Lacan ter acompanhado e escutado durante um tempo razoável a então paciente psiquiátrica.

0 outro grande caso clínico de psicose examinado por Lacan éo mesmo de Freud, o de Schreber, igualmente um caso de paranoia, extensamente estudada com base em uma releitura da autobiografia daquele, cotejada com a análise pioneira de Freud, mas aqui já falamos da década de 1950. Para falar um pouco esquematicamente, um terceiro momento na obra de Lacan quanto a um olhar para as psicoses, na década de 1970, são as reflexões sobre o escritor James Joyce, que não é um caso de paranoia, e nem sequer recebe alguma outra clara classificação psicótica, mas que coloca o problema sobre a loucura em um sentido mais amplo, na medida em que mesmo a identificação de uma psicose em Joyce é colocada em dúvida, ou como um problema teórico, pois se trata de em parte rever al gumas das considerações do período 195556 sobre o real, o simbólico e o imaginário, ou mais explicitamente, sobre as questões que envolvem o Nome-do-Pai e a metáfora paterna.

Também quanto a Lacan ressurge, em nosso entendimento, o problema da relação entre clínica e história. A leitura estrutural que faz Lacan das psicoses é certamente um grande avanço com relação às hesitações freudianas diante do problema, nos permitindo ter uma visão mais lúcida sobre a relação entre psicanálise e psicose, e a própria possibilidade de uma clínica das psicoses. De outro lado, cabe problematizar a quase que completa ausência de crítica às instituições hospitalares psiquiátricas também em Lacan, como se os problemas do poder e da dominação se encontrassem em um terreno externo ao escopo da psicanálise. Apesar disso, aparece em Lacan uma recusa da ideia de loucura como doença mental (Lacan, 2006a), deslocando-se completamente, nesse sentido, do organicismo presente na psiquiatria e que ainda repercutia na obra de Freud. Assim como todo seu pensamento, o enunciado de que 0 inconsciente é estruturado como uma linguagem serve como ponto de partida não só para o entendimento das neuroses, mas também para 0 âmbito das psicoses. Do que se trata aqui é também da posição do significante, mas quanto às psicoses a relação entre real, simbólico e imaginário adquire um caráter de "amarração" com algumas importantes peculiaridades.
Tais podem também ser pensadas quanto ao que separa aquilo que foi postulado desde o período do caso Aimée do período do seminário sobre 0 Sinthoma. As diferenças dizem respeito não somente ao tema da loucura, mas há outros aspectos do pensamento de Lacan como, é o caso do conceito de reconhecimento (Safatle, 2006), que virão a ter incidência sobre seus últimos escritos. Não sendo possível aqui nos determos ao tema, não custa lembrar que a noção de reconhecimento no primeiro Lacan estava associado ao conceito de intersubjetividade e a uma determinada recepção de Hegel, que se mostrará de um outro modo a partir do anos 1960, notadamente quanto ao fato de que o desejo do Outro, nesta segunda fase, desloca o sentido da ideia de intersubjetividade como esta era então pensada na tradição fenomenológica. Além disso, um reconhecimento que não mais se ancora em um tipo de herança da intersubjetividade oriunda do jovem Hegel, o que nos permitiria traçar um paralelo com a abordagem das psicoses em Ronald Laing (1969b), visto que para este último é justamente da intersubjetividade que se trata quando falamos de psicoses e especialmente de esquizofrenia (Camargo, 2019).

No caso de Lacan, na maior parte de sua obra, não é da intersubjetividade que fala a psicanálise, nem mesmo 0 ato analítico. A questão central das psicoses para Lacan se refere ao conceito de foraclusão [Verwerfung] que se situa em um entendimento de que é a linguagem que demarca a existência do inconsciente e de uma subjetividade compreendida pelos registros do real, do simbólico e do imaginário. Assim como no caso de Freud o ponto de partida é o interno e o externo implicado no processo de denegação, só que no caso de Lacan o externo se referindo aquilo que retorna no real, fora do registro simbólico. Trata-se do que se processa na ordem significante e ao modo pelo qual se mostra a presença ou ausência do desejo do Outro, aqui concebendo-se a relação entre o desejo da mãe (DM) e o Nome-do-Pai. Conforme Lacan a psicose se instala quando ao interrogarmos a cadeia significante há algo que não foi representado no registro simbólico:

É em um acidente deste registro e do que nele se cumpre, a saber a foraclusão do Nome-do-Pai no lugar do Outro, e no fracasso da metáfora paterna, onde designamos o efeito que dá a psicose sua condição essencial, com a estrutura que a separa da neurose (Lacan, 2006b, p. 556).

Mas tal conceito de foraclusão torna-se visível quando novamente Lacan retorna a Freud e à noção de castração. É a partir de uma centralidade desta noção em toda sua teoria psicanalítica que decorre a importância daquilo que ele chamará de o Nome-do-Pai, em torno do qual, no plano da significação, se compreende a diferenciação entre neurose e psicose. Ao contrário do pessimismo de Freud, para Lacan é possível uma clínica das psicoses, desde que o método psicanalítico se rearranje com este outro tipo de analisandos que requerem um repensar a transferência. No retorno que Lacan propõe da obra freudiana nos anos 1950, retoma-se também a noção de Freud de que o aparelho psíquico, em conformidade ao princípio do prazer, possibilita que se estabeleçam dois momentos, o da afirmação (Bejahung) e a denegação (Verneinung). Ao retornar ao texto freudiano sobre a Verneinung Lacan (1988, p. 178) abre espaço para reconhecer a Bejahung como o ponto de partida da ordem simbólica. Neste seminário Lacan (1955-56) sugere que há na psicose algo anterior da efetivação da cadeia simbólica, algo que não chega a se efetivar, uma rejeição/foraclusão (Verwerfung): 
Previamente a qualquer simbolização - esta anterioridade não é cronológica, mas lógica - há uma etapa, as psicoses 0 demonstram, em que é possível que uma parte da simbolização não se faça. Essa etapa primeira precede toda a dialética neurótica que está ligada ao fato de que a neurose é uma palavra que se articula, na medida em que o recalcado e o retorno do recalcado são uma só e mesma coisa. Assim pode acontecer que alguma coisa de primordial quanto ao ser do sujeito não entre na simbolização, e seja não recalcado, mas rejeitado (Lacan, 1988, p. 100).

A foraclusão se refere assim a um significante primeiro, que se chamará Nome-do-Pai. Na ausência de inscrição deste significante haverá algo diferente do que se passa na Bejahung. Significa igualmente que o psicótico não está inserido na ordem fálica. É deste modo que aquilo que está dentro não encontra uma representação fora, como na neurose, sendo por consequência que aquilo que vem a ser abolido internamente retorna desde fora, isto é, no real, enquanto alucinação. Lembremos que toda a exposição de Lacan no seminário de 1955-56 se dá no contexto de comentário ao texto autobiográfico de Schreber, sendo o exame da paranóia de Schreber, assim como o fora para Freud, o modelo de exposição quanto ao mecanismo da psicose, não se evidenciando, nesse contexto de explicitação do que é uma psicose, uma clara delimitação de diferenciação, por exemplo, entre paranoia e esquizofrenia, que nos permitisse entrever qual o mecanismo específico desta última quanto à foraclusão.

Consagrou-se o entendimento entre comentadores do campo lacaniano (Quinet, 2010; Soler, 2002) de que no seminário sobre o Sinthoma (1975-76) Lacan muda alguns aspectos de sua perspectiva sobre as psicoses. Sugiro dizer que na verdade sobre a loucura. A complexa exposição sobre os nós borromeanos traz de volta a problemática dos anos 1950 sobre a metáfora paterna, se tratando neste segundo momento de um repensar o papel do Nome-do-Pai, ou, o papel de sua ausência, quanto a um registro não mais apreensível na ordem simbólica do Real, Simbólico e Imaginário. A questão está em pensar em que o Real é um não lugar, e sendo a psicose, anteriormente concebida, como àquilo que retorna no Real, ressurge agora, a partir da figura de Joyce, sobre o como pensar uma psicose que não se apresenta enquanto tal.

Entendo que no Seminário sobre o Sinthoma quando Lacan pergunta se Joyce era um louco, é diferente de perguntar se Joyce era um psicótico. A concepção de estrutura psicótica me parece trazer um problema que se traduzirmos em uma linguagem coloquial equivaleria a dizer"louco ele é, só que não surtou ainda", na medida em que o sujeito encontrou uma solução original para aquilo que fugiu do simbólico (uma lalingua) conforme 0 próprio vocabulário lacaniano. Assim sendo, seja pela escrita, como no caso de Joyce, ou de alguma outra produção artística que venha a se apresentar como um quarto nó borromeu, como um enodamento que ultrapassa o Real, Simbólico e Imaginário, o sujeito psicótico encontra uma solução para a sua singularidade, mas que, afinal de contas, para muitos continua ser a evidência de sua anormalidade, visto que a "estrutura psicótica" está lá, cabendo à interpretação do psicanalista enxergar que solução foi encontrada para a suplência do Nome-do-Pai.

\section{Loucura e experiência}

A história da loucura e da esquizofrenia expressa uma tensão entre laço e experiência social. Se o laço social, em acepção lacaniana, também se refere a Lei e ao Nome-do-Pai, há que concebermos que as psicoses, e mais especificamente a esquizofrenia, aponta para uma experiência, dado o tipo de solução encontrada para aquilo que foi denegado e buscou um escape para além das possibilidades do simbólico. Podemos falar de situações psicóticas que encontram estabilização, e outras, ou momentos, que permeiam situações conflitivas e causadoras de sofrimento. No ambiente social do louco encontramos a família, como espectro microssocial, onde se inscrevem as primeiras experiências formadoras da subjetividade, mas não termina nela, na medida em que em um mundo de necessidade (Adorno, 2007, pp. 229235) a psique se situa dentro da história, e esta, enquanto sociedade, envolve diferentes dimensões como as do trabalho, das instituições e da moralidade, e enquanto totalidade, o capitalismo.

Na década de 1950 Michel Foucault, Jacques Lacan e Ronald Laing, representaram três diferentes vertentes epistemológicas e de circunscrição de campos do saber, sobre o pensar as psicoses. Foucault preocupou-se não com os conceitos e classificações de neurose, psicose e perversão, como na psicanálise, mas com a experiência da loucura, em sentido mais amplo, pois esta não se trata para ele de al gum tipo de nosografia, mas pelo contrário, de uma crítica da própria possibilidade de classificação. Crítica esta que se dirigia à medicina e à psiquiatria, mas também à psicanálise, com a qual Foucault nunca conseguiu manter uma relação plenamente amistosa, não apenas em termos teóricos, mas quanto às suas próprias experiências biográficas. Mesmo que Foucault e Lacan tenham tido algumas referências em comum em suas origens, quanto ao estruturalismo francês (Dosse, 1997), estiveram em suas obras em posições epistemológicas um pouco distintas.

Poderíamos falar de uma diferença entre 0 olhar da psicanálise e o olhar da sociologia, ou teoria social, para o fenômeno da loucura (Jaccard, 1981, p. 53), mas talvez fosse mais prudente falarmos da diferença entre uma certa forma de enxergar a psicanálise e uma teoria social crítica. 0 fato de Foucault usar na maior parte de seus textos a palavra loucura, ao invés de psicose, está longe de ser um apego a um conceito não mais usual, pelo contrário, se trata de uma escolha epistemológica, de recusar a própria conceituação de psicose para se referir às anormalidades. Em um primeiro olhar pode parecer que Foucault e a psicanálise estão falando de coisas diferentes quando o tema são as psicoses, mas o que está em questão, para uns e outros, é o estatuto da anormalidade. Há um substrato evidente que é o que podemos genericamente chamar de sofrimento psíquico, que se refere na psicanálise às formações do inconsciente, e para Foucault às relações de biopoder.

Já a antipsiquiatria britânica tentou abordar o fenômeno das psicoses por um outro caminho, enraizado em outro viés quanto a abordagem da relação entre sujeito e objeto, o eu e o outro, e quanto à constituição da loucura na sociedade contemporânea. Absorvendo parte da tradição psicanalítica, em especial Winnicott, e sem se contrapor aos desdobramentos da História da Loucura de Foucault, a raiz epistêmica de Laing e Cooper, se concebermos 0 contexto filosófico francês dos anos 1950, não é o estruturalismo, mas o seu oposto nos debates de então, o existencialismo sartreano e a tradição fenomenológica. A loucura, e em especial a esquizofrenia, para os antipsiquiatras londrinos, dizia respeito à uma experiência existencial, que nada tem a ver com doença mental, e que vê a psiquiatria como uma das principais formas de violência da contemporaneidade (Laing, 1969a). 
Enquanto para Freud e Lacan a loucura, quase sempre nomeada como psicose, buscou compreensão principalmente através de alguns casos clínicos de paranoia, como os famosos Schreber e Aimée, para os pensadores e militantes da antipsiquiatria a pesquisa sobre a esquizofrenia sempre foi seu interesse principal. Uma, senão a principal razão para isso, está no fato de que ao longo de quase todo o século XX houve uma forte associação, no campo da psiquiatria, entre loucura e esquizofrenia (Szasz, 1978), inclusive quanto à experiência empírica e histórica das instituições hospitalares manicomiais, nas quais a maior parte dos pacientes era diagnosticado como esquizofrênicos.

A esquizofrenia nunca deixou de ser um problema para a psicanálise, não obstante todos os avanços dados por esta última em tentar constituir uma clínica das psicoses (Calligaris, 1989). A maneira diferente com que Lacan e Laing nos anos 1950 e 1960 veem o fenômeno das psicoses reflete suas diferenças filosóficas. Para Lacan as psicoses, tal como as neuroses, buscam explicação em uma estrutura simbólica, que estruturada enquanto linguagem, produz o próprio sujeito e seu Outro, ou este aquele, onde a experiência infantil envereda para a formação de um inconsciente a céu aberto, que não encontra expressão no registro simbólico. Já para Laing, ao contrário de Lacan, a psicose tem uma dimensão claramente intersubjetiva em sua constituição (Camargo, 2019). 0 Eu, mesmo o psicótico, não se compreende em sua relação a o Outro, mas ao outro das relações pessoais, ao laço social intersubjetivo que se estabelece, para além das relações edipianas e da castração, como algo que se dá entre 0 indivíduo e seu contexto microssocial, especialmente familiar. Tanto quanto como para a psicanálise lacaniana, para a antipsiquiatria de Laing pesa a centralidade da linguagem, mas para estes últimos enquanto forma de comunicação interpessoal, quanto aos modos pelos quais especialmente no âmbito de uma experiência familiar (Laing \& Esterson, 1977) se constituem códigos e padrões de relacionamento que tornam possível 0 advento do indivíduo psicótico, ou esquizofrênico.

Isto também nos permite retomar as considerações feitas acima sobre 0 Joyce de Lacan e como pensar a relação entre loucura, psicose e diferença. A pergunta de Lacan se Joyce era louco não foi plenamente respondida, senão pela sugestão de que o escritor dublinense encontrou na escrita, em uma escrita bastante singular, um outro tipo de suplência para o buraco deixado pelo Nome-do-Pai, enxergando em lalíngua um escape da estrutura psicótica que, de qualquer modo, para alguns parece estar lá. Sugere-se assim que, tal como nas soluções de sublimação (Lacan, 2008), que envolvem as atividades criativas e artísticas, há algo denegado, e não representado na ordem das neuroses, que encontraria em alguma forma de arte, religião ou fazer científico, a saída que tangencia o enlouquecimento psicótico, ou que estabiliza sua loucura sem que a ele atribua o nome de uma psicose. É assim que muitos do nosso universo circundante são loucos do al to de sua aparente normalidade, notadamente em uma sociedade em que a lógica identificante (Adorno, 2009) se tornou a norma de unidimensionalidade.

\section{Considerações finais}

Quando caminhamos pelas ruas de alguma grande cidade e nos deparamos com um indivíduo, geralmente de aparência pauperizada e fisicamente degradada, falando "sozinho", somos por um lado apanhados pela crueza daquilo que chamamos delírios e alucinações, levando-nos a supor, portanto, que aí está um psicótico. Por outro lado, quando impera o senso comum, se estabelece uma representação social de que ali está al guém que causa risos ou medo, pois
0 acting out pode redundar em violência, como Aimée que em seu delírio de perseguição desferia uma facada em Huguette Dulfos. Aqui talvez se evidencie possíveis diferenças entre o campo psicanalítico e a tradição da antipsiquiatria, que se refere a um entendimento do que podemos chamar de social. Para Ronald Laing, por exemplo, haveria na origem das psicoses algo como uma experiência social, historicamente ancorada em uma realidade conflituosa, que em outros termos também é comparável à noção de poder de Michel Foucault.

A antiga antipsiquiatria britânica pode ser acusada de certo romantismo, superficialidade teórica e impulso político em sua forma de apreensão das psicoses. Mas em seu ímpeto militante provavelmente tem algo a nos dizer sobre 0 como as desigualdades sociais permeiam 0 universo da loucura, para além da clínica. 0 que, aliás, pode nos fazer pensar sobre a relação entre psicanálise e sociedade quanto ao posicionamento da teoria das pulsões em um olhar dialético (Adorno, 2007). 0 que nos motiva a pensar sobre o que seria uma teoria social crítica das psicoses.

Ao mesmo tempo, a psicanálise, com suas instituições, há muito tem dado demonstrações de uma vontade coletiva de intervenção na Polis, tanto mais quando se interpõe a própria possibilidade de uma sociedade democrática, condição necessária para a própria existência da psicanálise como campo do saber. Seria o caso, podemos sugerir, de pensar permanentemente sobre como direcionar esta intervenção para a dimensão social da loucura e das instituições a ela adjacentes, buscando compreender, sem a abdicação da teoria psicanalítica, o lugar em que situa a multiplicidade de singularidades que indicam em inúmeras circunstâncias sofrimento, em outras, e por vezes ao mesmo tempo, uma experiência social atravessada pela não identidade.

\section{Referências}

Adorno, T.W. (1986). O ensaio como forma (pp.167-187). São Paulo: Ática: 1986.

Adorno, T.W. (2007). Ensaios sobre psicologia social e psicanálise. São Paulo: Unesp.

Adorno, T. W. (2009). Dialética negativa. Rio de Janeiro: Zahar.

Birman, J. (1989). Freud e a crítica da razão delirante. In: BIRMAN, Joel (Org.). Freud - 50 anos Depois (pp. 133-148). Rio de Janeiro: Relume Dumará.

Bosseur, C. (1976). Introdução à antipsiquiatría. Rio de Janeiro: Zahar.

Calligaris, C. (1989). Introdução a uma clínica diferencial das psicoses. Porto Alegre: Artes Médicas.

Camargo, S. (2019). Esquizofrenia e experiência social: Ioucura, crítica e reconhecimento. Estudos Contemporâneos da Subjetividade, 9(2) 295-307.

Cooper, D. (1967). Psiquiatria e antipsiquiatria. São Paulo: Perspectiva.

Cooper, D. (1978). A Linguagem da loucura. Lisboa: editorial Presença.

Deleuze, G. e Guattari, F. (2010). O Anti-Édipo. São Paulo: Editora 34.

Dosse, F. (1997). History of Structuralism. Vol. I.: London: University of Minnesota Press.

Foucault, M. (1999). Les anormaux. Paris: Gallimard.

Foucault, M. (2014). História da loucura. São Paulo: Perspectiva.

Foucault, M. (2017). Microfísica do poder. Rio de Janeiro: Paz e Terra.

Freud, S. (1996). As neuropsicoses de defesa. In: S. Freud. Obras completas, V.3 (pp. 53-65). Rio de Janeiro: Imago. Obra originalmente publicada em 1894.

Freud, S (2015a). Introdução ao narcisismo. In: S. Freud: Obras completas, V. 12 (pp. 13-50). São Paulo: Companhia das Letras. Obra originalmente publicada em 1914.

Freud, S. (2015b). 0 Inconsciente. In: S. Freud: Obras completas, V. 12 (pp. 99-150). São Paulo: Companhia das Letras. Obra originalmente publicada em 1915. 
Freud, S (2016a). Observações psicanalíticas sobre um caso de paranoia relatado em autobiografia - "O Caso Schreber". In. S. Freud: Obras completas, V. 10 (pp. 13-107). São Paulo Companhia das Letras. Obra originalmente publicada em 1911.

Freud, S. (2016b). Neurose e psicose. In: S. Freud: Obras completas, V. 16 (pp. 176-183). São Paulo: Companhia das Letras. Obra originalmente publicada em 1924.

Freud, S. (2016c). A perda da realidade na neurose e na psicose. In: S. Freud: Obras completas, V. 16 (pp. 214-221). São Paulo: Companhia das Letras. Obra originalmente publicada em 1924.

Freud, S. (2016d). A negação. In: S. Freud: Obras completas, V. 16. São Paulo: Companhia das Letras. pp. 275-282. 2016e. Obra originalmente publicada em 1925.

Jaccard, R. (1981). A Loucura. Rio de Janeiro: Zahar.

Lacan, J. (1988). As psicoses. O Seminário, livro 3. Rio de Janeiro: Zahar.

Lacan, J. (2006a). Acerca de la causalidade psíquica. Obras escogidas I. (pp. 142-183). Barcelona: RBA Coleccionables.

Lacan, J. (2006b). De una cuestión preliminar a todo tratamento posible de las psicoses. Obras escogidas / (pp. 513-564). Barcelona: RBA Coleccionables.

Lacan, J. (2007). O Sinthoma. 0 Seminário, livro 23. Rio de Janeiro: Zahar.

Lacan, J. (2008). A Ética da psicanálise. O Seminário. Livro 7. Rio de Janeiro: Zahar.

Lacan, J. (2009). Os escritos técnicos de Freud. O Seminário, livro 1. Rio de Janeiro: Zahar.

Laing, R. (1969a). The Divided self. London: Penguin.

Laing, R. (1969b). Self and others. London: Penquin.

Laing, R. and Esterson, A. (1977). Sanity, madness and the family. London: Penguin

Leader, D. (2011). 0 Que é loucura? Delírio e sanidade na vida cotidiana. Rio de Janeiro: Zahar.

Quinet, A. (2010). Psicose e laço social. Rio de Janeiro: Zahar.

Roudinesco, E. (1994). Jacques Lacan. Esboço de uma vida, história de um sistema de pensamento. São Paulo: Companhia das Letras.

Safatle, V. (2006). A Paixão do negativo. Lacan e a dialética. São Paulo: Unesp. Soler, C. (2002). O Inconsciente a céu aberto da psicose. Rio de Janeiro: Zahar. Soler, C. (2018). Lacan, leitor de Joyce. São Paulo: Aller editora.

Szasz, T. (1978). Esquizofrenia. O símbolo sagrado da psiquiatria. Rio de Janeiro: Zahar. 